\title{
Asthma predictive index as a useful diagnostic tool in preschool children: a cross-sectional study in Korea
}

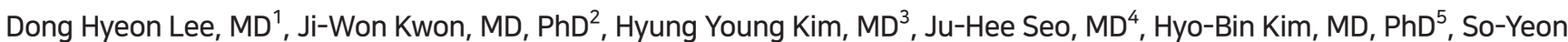
Lee, MD, PhD' ${ }^{6}$, Gwang-Cheon Jang, MD, PhD ${ }^{7}$, Dae-Jin Song, MD, PhD ${ }^{8}$, Woo Kyung Kim, MD, PhD ${ }^{9}$, Young-Ho Jung, MD, $\mathrm{PhD}^{6}$, Soo-Jong Hong, MD, $\mathrm{PhD}^{6}$, Jung Yeon Shim, MD, $\mathrm{PhD}^{1}$

${ }^{1}$ Department of Pediatrics, Kangbuk Samsung Hospital, Sungkyunkwan University School of Medicine, Seoul, Korea; ${ }^{2}$ Department of Pediatrics, Seoul National University Bundang Hospital, Sungnam, Korea; ${ }^{3}$ Department of Pediatrics, Pusan National University Yangsan Hospital, Yangsan, Korea; ${ }^{4}$ Department of Pediatrics, Korea Cancer Center Hospital, Seoul, Korea; ${ }^{5}$ Department of Pediatrics, Inje University Sanggye Paik Hospital, Seoul, Korea; ${ }^{6}$ Department of Pediatrics, Childhood Asthma Atopy Center, Research Center for Standardization of Allergic Diseases, Asan Medical Center, University of Ulsan College of Medicine, Seoul, Korea; ${ }^{7}$ Department of Pediatrics, National Health Insurance Corporation Ilsan Hospital, Goyang, Korea; ${ }^{8}$ Department of Pediatrics, Korea University Guro Hospital, Korea University College of Medicine, Seoul, Korea; ${ }^{2}$ Department of Pediatrics, Inje University Seoul Paik Hospital, Seoul, Korea

Background: It is challenging to diagnose asthma in preschool children. The asthma predictive index (API) has been used to predict asthma and decide whether to initiate treatment in preschool children.

Purpose: This study aimed to investigate the association between questionnaire-based current asthma with API, pulmonary function, airway hyperreactivity (AHR), fractional expiratory nitric oxide (FeNO), and atopic sensitization in preschool children.

Methods: We performed a population-based cross-sectional study in 916 preschool children aged 4-6 years. We defined current asthma as the presence of both physician-diagnosed asthma and at least one wheezing episode within the previous 12 months using a modified International Study of Asthma and Allergies in Childhood questionnaire. Clinical and laboratory parameters were compared between groups according to the presence of current asthma.

Results: The prevalence of current asthma was 3.9\% in the study population. Children with current asthma showed a higher rate of positive bronchodilator response and loose and stringent API scores than children without current asthma. The stringent API was associated with current asthma with 72.2\% sensitivity and $82.0 \%$ specificity. The diagnostic accuracy of the stringent API for current asthma was 0.771 . However, no intergroup differences in spirometry results, methacholine provocation test results, FeNO level, or atopic sensitization rate were observed.

Conclusion: The questionnaire-based diagnosis of current asthma is associated with API, but not with spirometry, AHR, FeNO, or atopic sensitization in preschool children.
Key words: Asthma, Preschool child, Wheezing, Allergy, Diagnosis

\section{Key message}

Question: Is physician-diagnosed current asthma in preschool children associated with the asthma predictive index, atopic sensitization, or pulmonary function test?

Finding: Physician-diagnosed current asthma in preschool children was associated with the asthma predictive index, but not with spirometry, methacholine provocation test, fractional expiratory nitric oxide level, and atopic sensitization.

Meaning: Physician-diagnosed asthma in preschool children may be different from classic atopic asthma in school children or adolescents.

\section{Introduction}

Asthma is the most prevalent chronic lower respiratory disorder in children worldwide. ${ }^{1)}$ The course of asthma varies from spontaneous remission to symptoms with repeated ag. gravation during the lifetime. The diagnosis of asthma and the control of its symptoms are very important, because asthma greatly influences public healthcare as well as a person's quality of life. ${ }^{2)}$

Some factors, such as atopic dermatitis (AD), allergic rhinitis (AR), wheeze, and parental asthma are used as predictive risk factors, and several tests, including spirometry, fractional expiratory nitric oxide (FeNO), blood eosinophil counts, and methacholine provocation test, are known diagnostic tools for

\footnotetext{
Corresponding author: Jung Yeon Shim, MD, PhD. Department of Pediatrics, Kangbuk Samsung Hospital, Sungkyunkwan University School of Medicine, 29 Saemunanro, Jongno-gu, Seoul 03181, Korea 凶E-mail: jy7.shim@samsung.com, https://orcid.org/0000-0001-9367-2233

Co-corresponding author: Soo-Jong Hong, MD, PhD. Department of Pediatrics, Childhood Asthma Atopy Center, Research Center for Standardization of Allergic Diseases, Asan Medical Center, 86 Asanbyeongwon-gil, Songpa-gu, Seoul 05505, Korea

凶E-mail: sjhong@amc.seoul.kr, https://orcid.org/0000-0003-1409-2113

Received: 13 June, 2019, Revised: 26 October, 2019, Accepted: 3 November, 2019

This is an open-access article distributed under the terms of the Creative Commons Attribution Non-Commercial License (http://creativecommons.org/licenses/by$\mathrm{nc} / 4.0 /$ ) which permits unrestricted non-commercial use, distribution, and reproduction in any medium, provided the original work is properly cited. 
asthma. ${ }^{3)}$ However, the diagnosis of asthma in preschool children is very hard, because there is no golden standard for asthma diagnosis and the difficulty of performing some tests due to poor cooperations. ${ }^{1,4,5)}$

Spirometry, FeNO, methacholine provocation test, and bronchoalveolar lavage (BAL) can determine airway inflammation, airway hyperreactivity (AHR), and reversible airway obstruction; however, these cannot be performed reliably in younger children. Moreover, BAL is too invasive to perform in children. FeNO has been suggested as an indirect method for analyzing airway inflammation, but further research is needed to be widely used. ${ }^{5)}$

The asthma predictive index (API) was developed in 2000 using data from the Tucson Children's Respiratory Study to predict the risk of asthma development at school age in preschool children. It has been used for screening high-risk groups for asthma development. ${ }^{5)}$

The purpose of this study is to determine the association of current asthma to the API and other laboratory tests such as spirometry, FeNO, AHR, and atopic sensitization test and verify the diagnostic accuracy of the API. Our findings will help identify children at risk of asthma and initiate early treatment in preschool children.

\section{Methods}

\section{Study design}

We performed a population-based, cross-sectional study involving 16 preschools in Seoul and Gyeonggi province, Korea. A total of 916 preschool children whose parents or guardians answered to the question regarding physician-diagnosed asthma and wheezing were enrolled. The questionnaire was based on the Korean version of modified International Study of Asthma and Allergies in Childhood questionnaire. ${ }^{6,7}$ Children who had ever been diagnosed with asthma by physician and had any wheezing episode within the last 12 months before the questionnaire were categorized as "current asthma."

To analyze the results, "recurrent wheeze" was defined as lifetime wheezes of 3 or more episodes based on the questionnaire. The "current" was defined as having symptoms or treatments within the last 12 months of answering the questionnaire, and "lifetime" was defined as having symptoms or treatments at any point in life.

Only children who could afford the tests and had not taken any medication or shown symptoms of respiratory infections within 1 month performed spirometry $(n=482)$, FeNO $(n=$ $372)$, methacholine provocation test $(n=212)$, and skin prick test $(n=648)$. All tests were performed by the same well-trained technicians to ensure standardization of the results. ${ }^{8)}$

Outcome variables were the prevalence of allergic diseases, hospitalization or Emergency Department (ED) visit, atopic sensitization, blood eosinophil counts, serum IgE levels, forced expiratory volume in 1 second ( $\left.F E V_{1}\right)$, bronchodilator response
Table 1. Asthma predictive index

\begin{tabular}{|c|c|}
\hline Criteria & No. (\%) \\
\hline \multicolumn{2}{|l|}{ Major criteria } \\
\hline Parental history of asthmaa) & $83 / 744(11.2)$ \\
\hline Physician-diagnosed atopic dermatitis ${ }^{\text {b) }}$ & $319 / 907(35.2)$ \\
\hline \multicolumn{2}{|l|}{ Minor criteria } \\
\hline Physician-diagnosed allergic rhinitis $\left.{ }^{b}\right)$ & 220/906 (24.3) \\
\hline Wheeze without colds ${ }^{c)}$ & $229 / 915(25.0)$ \\
\hline Blood eosinophil count $\geq 4 \%$ & $269 / 666(40.4)$ \\
\hline \multicolumn{2}{|c|}{$\begin{array}{l}\text { Stringent index, } 3 \text { or more wheezing episodes plus at least } 1 \text { major criteri } \\
\text { or } 2 \text { minor criteria; loose index, less than } 3 \text { episodes of wheezing plus a } \\
\text { least } 1 \text { major criteria or } 2 \text { minor criteria } \\
\text { a)History of physician-diagnosed asthma. }{ }^{\text {b) }} \text { Diagnosis at age } 2 \text { or } 3 \text { years. } \\
\text { History of wheezing episode that occurred at any time other than colds. }\end{array}$} \\
\hline
\end{tabular}

(BDR), FeNO, and AHR and compared between preschool children with and without current asthma

The API was assessed on the basis of factors in the questionnaire and blood eosinophil counts. (Table 1).9) The stringent index implies 3 or more wheezing episodes plus at least 1 major criteria or 2 minor criteria, and the loose index implies less than 3 episodes under the same conditions. ${ }^{5,9,10)}$

The study protocol was approved by the Institutional Review Board (IRB) of the University of Ulsan College of Medicine (IRB No. 2010-02 CON-14-P). Written consent was obtained after all the participants' parents or guardians were provided sufficient information about the details of the study.

\section{Fractional exhaled nitric oxide}

FeNO was measured using a Niox Mino device (Aerocrine, Solna, Sweden) as described in a previous study. ${ }^{6,8)}$ The mean value of the 3 measurements was recorded as the final FeNO.

\section{Pulmonary function test}

Spirometry was performed using VMAX 22 (Sensormedics, Anaheim, CA, USA) as described in a previous study. ${ }^{11)} \mathrm{BDR}$ was assessed by repeating the measurements 15 minutes after the inhalation of $200 \mathrm{mg}$ of salbutamol, ${ }^{12)}$ and a positive BDR was defined as a greater than $12 \%$ increase in $\mathrm{FEV}_{1}$ after bronchodilator inhalation.

\section{Methacholine provocation test}

Methacholine challenge tests were performed using the same method as described in a previous study. ${ }^{13)}$ AHR was defined when the concentration of methacholine required to induce a $20 \%$ decrease in $\mathrm{FEV}_{1}$ was lower than $8 \mathrm{mg} / \mathrm{mL}$. The doseresponse slope was defined as the $\%$ decline of $\mathrm{FEV}_{1}$ divided by the final cumulative methacholine dose administered.

\section{Measurement of serum total IgE concentrations and blood eosinophil counts}

Serum total $\mathrm{IgE}$ concentrations were measured using an Im. munoCAP (ThermoFisher Scientific, Uppsala, Sweden). Blood eosinophil counts were obtained using an automatic blood cell counter (XE-100, Sysmex, Kobe, Japan). The results were con- 
verted to logarithmic values for analysis.

\section{Atopic sensitization}

A skin prick test (Allergopharma, Reinbek, Germany) using 16 common allergens (12 aeroallergens and 4 food allergens) was performed as previously mentioned. ${ }^{8)}$ The test was considered positive when the mean wheal size in response to an allergen was greater than $3 \mathrm{~mm}$ and at least equal to or greater than the mean wheal size in response to histamine. Atopic sensitization was defined as a positive skin prick test for any allergen.

\section{Statistical analysis}

Statistical analyses were performed using STATA ver. 11.0 (StataCorp LP, College Station, TX, USA). The mean values were compared between the 2 different groups by using Student $t$ test. The significance of between-group differences in categorical variables between groups was tested using chi-square analysis.

Multivariate logistic regression was used to determine the associations of the API parameters with current asthma. Adjusted odds ratios and $95 \%$ confidence intervals were derived after adjusting for age, sex, height, and weight. All data were expressed as means \pm standard deviations or number (\%), and significance was defined as a $P$ value less than 0.05 .

\section{Results}

\section{Demographics and clinical characteristics of the study sub- jects}

The mean age of the study subjects was 58.4 months, and 51.3 $\%$ were male. The prevalence of lifetime wheeze and recurrent wheeze was $25.0 \%$ and $13.3 \%$, respectively. The prevalence of physician-diagnosed current asthma was 3.9\% and the rate of physician-diagnosed lifetime asthma, $\mathrm{AR}$, and $\mathrm{AD}$ was $8.4 \%$, $24.3 \%$, and $35.2 \%$, respectively. Parental history of asthma was

Table 2. Clinical characteristics of the study subjects

\begin{tabular}{lc}
\hline Variable & Value \\
\hline Age (mo) & $58.4 \pm 12.6$ \\
Male sex & $470 / 916(51.3)$ \\
Lifetime wheeze & $229 / 915(25.0)$ \\
Recurrent wheeze 3 & $119 / 897(13.3)$ \\
Physician-diagnosed current asthma & $36 / 880(3.9)$ \\
Physician-diagnosed lifetime asthma & $76 / 904(8.4)$ \\
Physician-diagnosed lifetime AR & $220 / 906(24.3)$ \\
Physician-diagnosed lifetime AD & $319 / 907(35.2)$ \\
Parental history of asthma & $83 / 744(11.2)$ \\
Current hospitalization owing to wheezing & $18 / 125(14.4)$ \\
Lifetime hospitalization owing to wheezing & $74 / 171(43.3)$ \\
Current ED visits owing to wheezing & $16 / 159(10.1)$ \\
Lifetime ED visits owing to wheezing & $58 / 200(29.0)$ \\
Atopic sensitization & $144 / 648(22.2)$ \\
Blood eosinophil count 4\% & $269 / 666(40.4)$ \\
\hline Vales are presented as meantstandard devation or number
\end{tabular}

Values are presented as mean \pm standard deviation or number (\%).

$A D$, atopic dermatitis; AR, allergic rhinitis; ED, Emergency Department. present in $11.2 \%$. The rates of current and lifetime hospitalizations owing to wheezing were $14.4 \%$ and $43.3 \%$, respectively. The rates of current and lifetime ED visits owing to wheezing were $10.1 \%$ and $29.0 \%$, respectively (Table 2 ).

\section{Comparison of clinical and laboratory parameters between children with and without current asthma}

We compared the prevalence of allergic diseases, hospitalization or ED visit owing to wheezing, parental history of allergic diseases, and atopic sensitizations between the 2 groups. No significant differences were observed in age and sex. Children with current asthma showed a higher prevalence of physiciandiagnosed AR. The prevalence of hospitalization and current $\mathrm{ED}$ visit owing to wheezing was higher in children with current asthma. Children with current asthma also had a higher rate of parental asthma and positive BDR. The proportion of positive APIs significantly increased in children with current asthma. However, no differences were observed in blood eosinophil counts, FeNO, AHR, and atopic sensitization between the 2 groups (Table 3).

Table 3. Clinical and laboratory characteristics of preschool children with versus those without current asthma

\begin{tabular}{|c|c|c|c|}
\hline Variable & $\begin{array}{l}\text { Current asthma } \\
\qquad(-)(n=880)\end{array}$ & $\begin{array}{l}\text { Current asthma } \\
\qquad(+)(n=36)\end{array}$ & $\begin{array}{c}P \\
\text { value }\end{array}$ \\
\hline Age (mo) & $58.4 \pm 12.6$ & $61.9 \pm 11.2$ & 0.10 \\
\hline Male sex & $449(51.0)$ & $21(58.3)$ & 0.40 \\
\hline Recurrent wheeze 3 & $90 / 861(10.5)$ & 29/36 (80.6) & 0.00 \\
\hline Physician-diagnosed AR & 199/870 (22.9) & $21 / 36(58.3)$ & 0.00 \\
\hline Physician-diagnosed AD & $301 / 871(34.6)$ & $18 / 36(50.0)$ & 0.07 \\
\hline $\begin{array}{l}\text { Current hospitalization owing } \\
\text { to wheezing }\end{array}$ & 9/104 (8.65) & $9 / 21(42.9)$ & 0.00 \\
\hline $\begin{array}{l}\text { Lifetime hospitalization owing } \\
\text { to wheezing }\end{array}$ & $55 / 141$ (39.0) & 19/30 (63.3) & 0.02 \\
\hline $\begin{array}{l}\text { Current ED visit owing to } \\
\text { wheezing }\end{array}$ & $9 / 138(6.5)$ & $7 / 21(33.3)$ & 0.001 \\
\hline $\begin{array}{l}\text { Lifetime ED visit owing to } \\
\text { wheezing }\end{array}$ & $45 / 169(26.6)$ & $13 / 31(41.9)$ & 0.09 \\
\hline Parental history of asthma & 73/708 (10.3) & $10 / 34(29.4)$ & 0.002 \\
\hline $\log \operatorname{TEC}\left(/ \mathrm{mm}^{3}\right)$ & 5.40 .8 & 5.71 .1 & 0.11 \\
\hline loglgE (IU/mL) & 4.31 .3 & 4.81 .1 & 0.12 \\
\hline FEV1 (\%pred) & 96.115 .1 & 96.015 .7 & 0.97 \\
\hline Positive BDR & $69 / 466(14.8)$ & $6 / 16(37.5)$ & 0.03 \\
\hline FeNO (ppb) & 10.56 .2 & 12.98 .1 & 0.22 \\
\hline DRS & 1.80 .6 & 1.60 .6 & 0.52 \\
\hline Positive AHR & $72 / 206$ (35.0) & 2/6 (33.3) & 0.93 \\
\hline Atopic sensitization & $137 / 626(21.9)$ & $7 / 22(31.8)$ & 0.29 \\
\hline Loose API & $185 / 880(21.0)$ & $27 / 36(75.0)$ & 0.00 \\
\hline Stringent API & $159 / 880(18.1)$ & $26 / 36(72.2)$ & 0.00 \\
\hline
\end{tabular}

Values are presented as mean \pm standard deviation or number (\%).

$A R$, allergic rhinitis; $A D$, atopic dermatitis; ED, Emergency Department; logTEC, logarithmic transformation of peripheral blood total eosinophil count; loglgE, logarithmic transformation of immunoglobulin $E_{;} F E V$ 1, forced expiratory volume in 1 second; BDR, bronchodilator response; FeNO, fractional exhaled nitric oxide; DRS, dose-response slope; AHR, airway hyperreactivity; API, asthma predictive index. 


\section{Association of the API categories with current asthma}

Multivariate logistic regression analyses were carried out to analyze the associations of the API with current asthma after adjusting for age, sex, weight, and height. The results showed that the API categories except for physician-diagnosed $\mathrm{AD}$ and blood eosinophil count $\geq 4 \%$ were significantly associated with current asthma. Both the stringent and loose APIs were associated with current asthma (Table 4).

\section{Diagnostic accuracy of the loose and stringent criteria for current asthma}

The loose and stringent APIs showed 75.0\% and 72.2\% sensitivity, respectively, and $79.0 \%$ and $82.0 \%$ specificity, respectively, for current asthma. The loose and stringent APIs had high negative predictive values (NPVs) of $98.7 \%$ and $98.6 \%$, respectively, but low positive predictive values (PPVs) of 12.7\% and $14.1 \%$, respectively. The positive likelihood ratio $(\mathrm{LR}+)$ and negative likelihood ratio (LR-) of the stringent API for current asthma were 4.0 and 0.3 , respectively, and LR + and LR- of the loose API were 3.6 and 0.3, respectively. The diagnostic accuracy

Table 4. Association between API and current asthma

\begin{tabular}{lcccc}
\hline Variable & No. (\%) & $P$ value & OR & $95 \% \mathrm{Cl}$ \\
\hline Major criteria & $23 / 34(67.7)$ & 0.004 & 3.26 & $1.47-7.26$ \\
Parental history of asthma & $10 / 34(29.4)$ & 0.002 & 4.30 & $1.92-9.63$ \\
Physician-diagnosed AD & $18 / 36(50.0)$ & 0.07 & 1.87 & $0.92-3.80$ \\
Minor criteria & $19 / 25(76.0)$ & 0.00 & 12.4 & $4.43-34.69$ \\
Physician-diagnosed AR & $21 / 36(58.3)$ & 0.00 & 6.20 & $2.91-13.21$ \\
Wheeze without cold & $34 / 36(94.4)$ & 0.00 & 59.15 & $13.91-251.6$ \\
Blood eosinophil count $\geq 4 \%$ & $15 / 25(60.0)$ & 0.06 & 2.05 & $0.86-4.91$ \\
Loose API & $27 / 36(75.0)$ & 0.00 & 13.03 & $5.48-30.00$ \\
Stringent API & $26 / 36(72.2)$ & 0.00 & 12.87 & $5.59-29.62$ \\
Recurrent wheeze $\geq 3$ & $29 / 36(80.6)$ & 0.00 & 33.63 & $13.87-81.54$
\end{tabular}

Data are adjusted for age, sex, weight, and height.

$O R$, odds ratio; $\mathrm{Cl}$, confidence interval; $A D$, atopic dermatitis; $A R$, allergic rhinitis; API, asthma predictive index. of the loose and stringent APIs was 0.770 and 0.771 , respectively (Table 5).

\section{Comparison of the API to other predictive models}

We compared the API in this study to other predictive models for asthma; the original API, ${ }^{9}$ the Prevention and Incidence of Asthma and Mite Allergy (PIAMA) risk score, ${ }^{3)}$ Isle of Wight score, ${ }^{14)}$ and asthma prediction tool (APT) ${ }^{15)}$ (Table 6). The API in this study showed higher LR+ and lower LR- compared to other predictive models for asthma except for the original API. The API in this study demonstrated the highest NPV and sensitivity compared to other predictive models, but lowest PPV.

\section{Discussion}

Several scoring systems have been developed to predict asthma, such as the API, ${ }^{1,9)}$ PIAMA, ${ }^{3,4,16)}$ Isle of Wight, ${ }^{14)}$ modified API, ${ }^{17)}$ APT ${ }^{15)}$ the severity score for obstructive airway disease, ${ }^{18)}$ and an extension of the severity score. ${ }^{19)}$ The API, PIAMA, and APT were only validated in new populations. Among these, the API is the most useful predictor of the likelihood of asthma because it is simple and derives from unselected multiracial population. ${ }^{20)} \mathrm{To}$ our knowledge, this is the first study to investigate the diagnostic utility of the API in preschool children in Korea. Unlike other prospective cohort studies, we used the data from a crosssectional study and evaluated the diagnostic accuracy. The API from cross-sectional study was shown to be suitable to ascertain asthma status with $89.5 \%$ agreement rate and 0.66 kappa. ${ }^{21)}$ In this study, the stringent API showed $72.2 \%$ sensitivity and $82.0 \%$ specificity with a diagnostic accuracy of 0.771 . The NPV was very high, suggesting that most children with a negative API may not have asthma. Our data showed that the API from crosssectional study can be used as a diagnostic tool for asthma with reasonable accuracy in preschool children.

Table 5. Diagnostic accuracy of loose and stringent API for current asthma

\begin{tabular}{lccccccc}
\hline Index & Sensitivity (\%) & Specificity (\%) & PPV (\%) & NPV (\%) & LR+ & LR- & Diagnostic accuracy \\
\hline Loose API & $75.0(57.8-87.9)$ & $79.0(76.1-81.6)$ & $12.7(8.6-18.0)$ & $98.7(97.6-99.4)$ & $3.6(2.8-4.5)$ & $0.3(0.2-0.6)$ & $0.770(0.70-0.84)$ \\
Stringent API & $72.2(54.8-85.8)$ & $82.0(79.2-84.4)$ & $14.1(9.4-19.9)$ & $98.6(97.5-99.3)$ & $4.0(3.1-5.1)$ & $0.3(0.2-0.6)$ & $0.771(0.70-0.85)$ \\
\hline
\end{tabular}

Numbers in parentheses indicate $95 \%$ confidence intervals.

API, asthma predictive index; PPV, positive predictive value; NPV, negative predictive value; LR+, positive likelihood ratio; LR-, negative likelihood ratio.

Table 6. Comparison of asthma predictive models

\begin{tabular}{|c|c|c|c|c|c|c|}
\hline Asthma predictive model & Sensitivity (\%) & Specificity (\%) & PPV (\%) & NPV (\%) & $\mathrm{LR}+$ & LR- \\
\hline KAPI (stringent index) & 72.2 & 82.0 & 14.1 & 98.6 & 4.0 & 0.3 \\
\hline \multicolumn{7}{|l|}{ API (stringent index) $)^{9)}$} \\
\hline At $6 \mathrm{yr}$ & 28 & 96 & 48 & 92 & 7.43 & 0.75 \\
\hline At $8 \mathrm{yr}$ & 16 & 97 & 44 & 88 & 4.9 & 0.86 \\
\hline PIAMA (cutoff $\geq 20$ ) at $7-8 \mathrm{yr}^{3}$ ) & 60 & 76 & 23 & 94 & 2.5 & 0.53 \\
\hline Isle of Wight (score strata $\geq 3$ ) at $10 \mathrm{yr}^{14}$ ) & 53 & 85 & 68 & 74 & 3.41 & 0.56 \\
\hline APT at 6-8 $\mathrm{yr}^{15)}$ & 72 & 71 & 49 & 86 & 2.5 & 0.4 \\
\hline
\end{tabular}

PPV, positive predictive value; NPV, negative predictive value; LR+, positive likelihood ratio; LR-, negative likelihood ratio; KAPI, Korean asthma predictive index; API, asthma predictive index; PIAMA, Prevention and Incidence of Asthma and Mite Allergy; APT, asthma predictive tool. 
In our study, physician-diagnosed $\mathrm{AD}$ was not associated with current asthma. The allergic march begins with $\mathrm{AD}$ and $\mathrm{AD}$ is one of high-risk factors for asthma. Asthma is known to develop in $60 \%$ of children with severe $\mathrm{AD}$ and $20 \%$ with mild $\mathrm{AD} .{ }^{22)}$ However, a retrospective analysis of 2 birth cohorts showed the proportion of children with both wheeze and eczema was only $5.8 \%{ }^{23)}$ In addition, while the prevalence of $\mathrm{AD}$ has doubled over the past decade, the prevalence of asthma has decreased by $50 \%$ in Korea. ${ }^{24)}$ The absence of increases in the prevalence of asthma has been observed globally, whereas the prevalence of $\mathrm{AD}$ and $\mathrm{AR}$ has seen a marked increase. ${ }^{24)}$ These findings indicate that the association between $\mathrm{AD}$ and asthma is relatively weak.

Parental history of asthma was significantly associated with current asthma in our study. This is supported by other studies that showed parental history of asthma to be a powerful risk factor for asthma in children. ${ }^{1,2,25)}$ Wheeze without cold was the most strongly associated with current asthma, as was recurrent wheeze. This may be in agreement with the findings of another study that showed frequent early wheeze to be the single most important predictor of asthma. ${ }^{10)}$

We also compared some test results, such as AHR, FeNO, and spirometry, between the 2 groups. Interestingly, current asthma was associated only with positive BDR, and not with atopic sensitization, AHR, FEV 1 , or FeNO. Asthma in preschool children may differ from late childhood or adult asthma. ${ }^{26}$ Wheezing episodes are mostly episodic and triggered by viral infection, rather than by allergens. Moreover, there is less time for disease progression in preschool children; hence, airway obstruction demonstrating decreased $\mathrm{FEV}_{1}$ is uncommon. Preschool children show less airway inflammation, fixed airway obstruction, basement membrane thickening, and AHR than adults, even in severe cases. $^{26)}$

In our study, current asthma was not associated with atopic sensitization, blood eosinophilia, and FeNO. Atopic sensitization has been found to be a risk factor for recurrent wheezing and associated with AHR, ${ }^{2,4)}$ and eosinophilic inflammation can be predominant in patients with atopic sensitization. FeNO is associated with airway eosinophilic inflammation; it was significantly correlated with eosinophils and eosinophil cationic protein of sputum, airway mucosal biopsy, or BAL fluid in asthmatic patients. ${ }^{27,28)}$ Our results may be attributed to the fact that most preschoolers with wheezing are virus-induced, non-atopic and may not exhibit eosinophilic inflammation. ${ }^{29}$

The prevalence of AHR, a typical characteristic of asthma assessed by the methacholine provocation test, showed no difference between the 2 groups in this study. Methacholine is a nonspecific direct stimulant acting on an airway smooth muscle receptor that results in bronchial constriction. Bronchoconstriction by methacholine is present not only in asthma but also in other acute and chronic airway inflammatory diseases. ${ }^{30)} \mathrm{Al}$. though AHR is the hallmark of asthma in older children and adults, a high frequency of negative methacholine test was reported in asthmatics. ${ }^{31)}$ In addition, young children may show different response to methacholine due to relatively underdeveloped airway and smooth muscle layer. A prospective study demonstrated that preschoolers who visited the ED owing to wheezing showed no difference in AHR from healthy preschoolers. ${ }^{32}$

This study has some limitations. First, because this was a cross-sectional study, it was impossible to confirm whether the children developed asthma later. However, we calculated the diagnostic accuracy of the API and we can further obtain the prognostic accuracy of the API for asthma development. Second, it was a questionnaire-based study completed by the parents or guardians, not by physician chart reviews; therefore, recall bias or incorrect diagnosis may be present. However, questionnairebased parent-reported wheezing showed a high agreement with physician-confirmed wheezing. ${ }^{33,34)}$ Finally, spirometry, bronchial provocation tests were difficult to perform in preschoolers since active cooperation is required, ${ }^{4)}$ which results in a small number of testers. However, this is the source of efforts to develop biomarkers or asthma predictive models for asthma.

Although many biomarkers such as eosinophil-derived neurotoxin, eosinophil cationic protein, periostin, or exhaled breath condensate have been studied for the predictors of asthma, no indicator has as yet been confirmed as gold standard for diagnosis or prediction of asthma in preschool children. Furthermore, there have been no studies related to the API except for periostin. Serum periostin levels showed no difference in preschool wheezers according to the API. ${ }^{35)}$ The API is inexpensive, less invasive, and has been validated by several studies, ${ }^{5,20)}$ and the diagnostic accuracy in this study is quite fair, so it can be used for asthma screening in preschool children. The strength of this study is that, unlike other studies, spirometry, AHR, FeNO, and BDR were evaluated in preschool children. ${ }^{20)}$ Together, our data is a population-based case-control study including mild asthma patients, unlike hospital-based studies including severe asthma patients. It can be applied to the other populations by representing the general population.

In conclusion, our results showed that the API was significantly associated with questionnaire-based current asthma in preschool children. The API may serve as a more reliable tool than spirometry, FeNO, methacholine provocation test, and atopic sensitization for diagnosing asthma in preschool children.

\section{Conflicts of interest}

No potential conflict of interest relevant to this article was reported.

See commentary "Is the predictive model for asthma development useful as a tool for diagnosing pediatric asthma?" in Volume 63 on 102.

\section{References}

1. Castro-Rodriguez JA. The Asthma Predictive Index: a very useful tool 
for predicting asthma in young children. J Allergy Clin Immunol 2010; 126:212-6.

2. Guilbert TW, Morgan WJ, Zeiger RS, Bacharier LB, Boehmer SJ, Krawiec $\mathrm{M}$, et al. Atopic characteristics of children with recurrent wheezing at high risk for the development of childhood asthma. J Allergy Clin Immunol 2004;114:1282-7.

3. Caudri D, Wijga A, A Schipper CM, Hoekstra M, Postma DS, Koppelman $\mathrm{GH}$, et al. Predicting the long-term prognosis of children with symptoms suggestive of asthma at preschool age. J Allergy Clin Immunol 2009;124: 903-10.

4. Caudri D, Wijga AH, Hoekstra MO, Kerkhof M, Koppelman GH, Brunekreef B, et al. Prediction of asthma in symptomatic preschool children using exhaled nitric oxide, Rint and specific IgE. Thorax 2010; 65:801-7.

5. Huffaker MF, Phipatanakul W. Utility of the Asthma Predictive Index in predicting childhood asthma and identifying disease-modifying interventions. Ann Allergy Asthma Immunol 2014;112:188-90.

6. Oh MA, Shim JY, Jung YH, Seo JH, Young Kim H, Kwon JW, et al. Fraction of exhaled nitric oxide and wheezing phenotypes in preschool children. Pediatr Pulmonol 2013;48:563-70.

7. Asher MI, Keil U, Anderson HR, Beasley R, Crane J, Martinez F, et al. International Study of Asthma and Allergies in Childhood (ISAAC): rationale and methods. Eur Respir J 1995;8:483-91.

8. Soh JE, Kim KM, Kwon JW, Kim HY, Seo JH, Kim HB, et al. Recurrent wheeze and its relationship with lung function and airway inflammation in preschool children: a cross-sectional study in South Korea. BMJ Open 2017;7:e018010.

9. Castro-Rodríguez JA, Holberg CJ, Wright AL, Martinez FD. A clinical index to define risk of asthma in young children with recurrent wheezing. Am J Respir Crit Care Med 2000;162:1403-6.

10. Leonardi NA, Spycher BD, Strippoli MP, Frey U, Silverman M, Kuehni CE. Validation of the Asthma Predictive Index and comparison with simpler clinical prediction rules. J Allergy Clin Immunol 2011;127:146672.

11. Lee JW, Shim JY, Kwon JW, Kim HY, Seo JH, Kim BJ, et al. Exhaled nitric oxide as a better diagnostic indicator for evaluating wheeze and airway hyperresponsiveness in preschool children. J Asthma 2015;52:1054-9.

12. Global Initiative for Asthma. Global Strategy for Asthma Management and Prevention, 2018. Available from: https://ginasthma.org.

13. Shim JY, Kim HB, Lee SY, Yu J, Kim WK, Kang D, et al. Effects of early measles on later rhinitis and bronchial hyperresponsiveness. Ann Allergy Asthma Immunol 2010;105:43-9.

14. Kurukulaaratchy RJ, Matthews S, Holgate ST, Arshad SH. Predicting persistent disease among children who wheeze during early life. Eur Respir J 2003;22:767-71.

15. Pescatore AM, Dogaru CM, Duembgen L, Silverman M, Gaillard EA, Spycher BD, et al. A simple asthma prediction tool for preschool children with wheeze or cough. J Allergy Clin Immunol 2014;133:111-8.

16. Hafkamp-de Groen E, Lingsma HF, Caudri D, Levie D, Wijga A, Koppelman $\mathrm{GH}$, et al. Predicting asthma in preschool children with asthma-like symptoms: validating and updating the PIAMA risk score. J Allergy Clin Immunol 2013;132:1303-10.

17. Chang TS, Lemanske RF Jr, Guilbert TW, Gern JE, Coen MH, Evans $\mathrm{MD}$, et al. Evaluation of the modified asthma predictive index in high-risk preschool children. J Allergy Clin Immunol Pract 2013;1:152-6.
18. Devulapalli CS, Carlsen KC, Håland G, Munthe-Kaas MC, Pettersen M, Mowinckel P, et al. Severity of obstructive airways disease by age 2 years predicts asthma at 10 years of age. Thorax 2008;63:8-13.

19. Lødrup Carlsen KC, Söderström L, Mowinckel P, Håland G, Pettersen M, Munthe Kaas MC, et al. Asthma prediction in school children; the value of combined IgE-antibodies and obstructive airways disease severity score. Allergy 2010;65:1134-40.

20. Castro-Rodriguez JA, Cifuentes L, Martinez FD. Predicting asthma using clinical indexes. Front Pediatr 2019;7:320.

21. Wi CI, Park MA, Juhn YJ. Development and initial testing of Asthma Predictive Index for a retrospective study: an exploratory study. J Asthma 2015;52:183-90.

22. Hill DA, Spergel JM. The atopic march: critical evidence and clinical relevance. Ann Allergy Asthma Immunol 2018;120:131-7.

23. Belgrave DC, Granell R, Simpson A, Guiver J, Bishop C, Buchan I, et al. Developmental profiles of eczema, wheeze, and rhinitis: two populationbased birth cohort studies. PLoS Med 2014;11:e1001748.

24. Asher MI, Montefort S, Björkstén B, Lai CK, Strachan DP, Weiland SK, et al. Worldwide time trends in the prevalence of symptoms of asthma, allergic rhinoconjunctivitis, and eczema in childhood: ISAAC Phases One and Three repeat multicountry cross-sectional surveys. Lancet 2006;368: 733-43.

25. Taussig LM, Wright AL, Holberg CJ, Halonen M, Morgan WJ, Martinez FD. Tucson Children's Respiratory Study: 1980 to present. J Allergy Clin Immunol 2003;111:661-75.

26. Gelfand EW. Is asthma in childhood different from asthma in adults? Why do we need special approaches to asthma in children? Allergy Asthma Proc 2008;29:99-102.

27. Warke TJ, Fitch PS, Brown V, Taylor R, Lyons JD, Ennis M, et al. Exhaled nitric oxide correlates with airway eosinophils in childhood asthma. Thorax 2002;57:383-7.

28. Berry MA, Shaw DE, Green RH, Brightling CE, Wardlaw AJ, Pavord ID. The use of exhaled nitric oxide concentration to identify eosinophilic airway inflammation: an observational study in adults with asthma. Clin Exp Allergy 2005;35:1175-9.

29. Brand PL, Baraldi E, Bisgaard H, Boner AL, Castro-Rodriguez JA, Custovic A, et al. Definition, assessment and treatment of wheezing disorders in preschool children: an evidence-based approach. Eur Respir J 2008;32:1096-110.

30. Cockcroft DW. Direct challenge tests: Airway hyperresponsiveness in asthma: its measurement and clinical significance. Chest 2010;138:18S24S.

31. Anderson SD, Brannan JD. Bronchial provocation testing: the future. Curr Opin Allergy Clin Immunol 2011;11:46-52.

32. Ater D, Bar BE, Fireman N, Fireman E, Shai H, Tasher D, et al. Asthmapredictive-index, bronchial-challenge, sputum eosinophils in acutely wheezing preschoolers. Pediatr Pulmonol 2014;49:952-9.

33. Mallol J, García-Marcos L, Aguirre V, Martinez-Torres A, Perez-Fernández V, Gallardo A, et al. The International Study of Wheezing in Infants: questionnaire validation. Int Arch Allergy Immunol 2007;144:44-50.

34. Chong Neto HJ, Rosario N, Dela Bianca AC, Solé D, Mallol J. Validation of a questionnaire for epidemiologic studies of wheezing in infants. Pediatr Allergy Immunol 2007;18:86-7.

35. Castro-Rodriguez JA, Atton I, Villarroel G, Serrano CA. Serum periostin is not related to asthma predictive index. Allergol Immunopathol (Madr) 2018;46:235-40. 